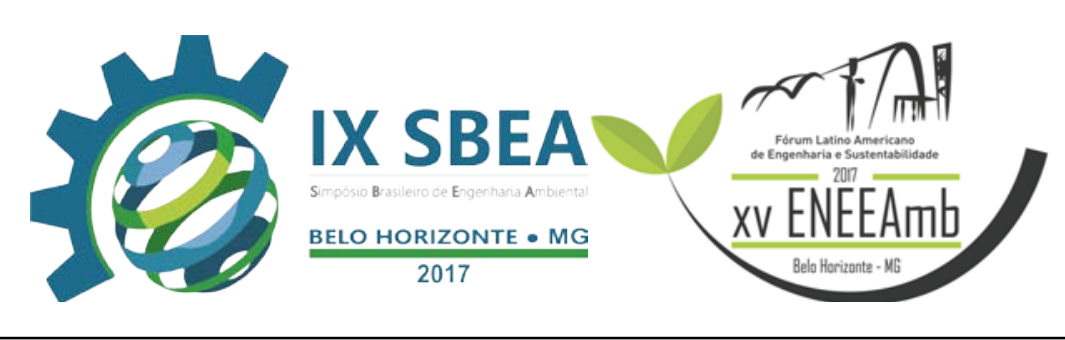

RESÍDUOS SÓLIDOS

\title{
DIAGNÓSTICO DA EFICÁCIA DO GERENCIAMENTO DOS RESÍDUOS SÓLIDOS EM UMA REGIÃO DE BELÉM DO PARÁ
}

\author{
Juliana Maia Duarte - duartemaiajuliana@gmail.com \\ Graduanda de Eng. Sanitária e Ambiental na Universidade Federal do Pará \\ Fábio Sergio Lima Brito - fabio.lima.ufpa@gmail.com \\ Graduando de Eng. Sanitária e Ambiental na Universidade Federal do Pará \\ Ana Paula Gomes Mendonça - anapaulagomesmendonca03@gmail.com \\ Graduanda de Eng. Sanitária e Ambiental na Universidade Federal do Pará \\ Rafaela Caroline Barros Silva - barrosrc15@gmail.com \\ Graduanda de Eng. Sanitária e Ambiental na Universidade Federal do Pará \\ Lindemberg Lima Fernandes - linlimfer@gmail.com \\ Prof. Doutor da FAESA na Universidade Federal do Pará
}




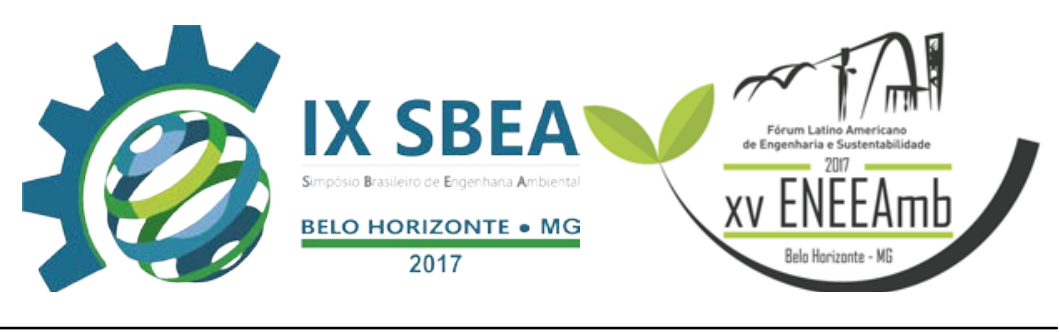

\section{RESUMO}

Os resíduos sólidos urbanos além de abranger as questões ambientas, relacionam também os conceitos sociais. O desenvolvimento de um projeto público adequado para a gestão dos resíduos sólidos urbanos está diretamente relacionado ao grau de envolvimento da população beneficiada. O objetivo do presente trabalho é diagnosticar a eficiência do gerenciamento dos resíduos sólidos em uma determinada área na cidade de Belém do Pará. Através de registros fotográficos foi possível explorar o local, no qual foram aplicados questionários a fim de obter o perfil do morador e os conhecimentos e hábitos do mesmo. Resultando na exposição de alguns problemas, como o mal condicionamento dos resíduos. Porém, apresentou-se também que isto pode ser conseqüência da ausência de algum treinamento sobre o correto manuseio e separação dos resíduos. Ademais, é necessário dispor de ações governamentais e propostas junto à população a fim de estabelecer metas para o avanço na resolução dos problemas encontrados, para a conservação do meio ambiente e qualidade de vida no local.

Palavras-chave: Resíduos sólidos urbanos Gestão integrada, População.

\section{INTRODUÇÃO/OBJETIVO}

Desde o século XX vem ocorrendo várias alterações ambientais significativas, como a poluição dos recursos hídricos, poluição do ar, aquecimento global, e uma super exploração dos recursos naturais. No entanto, em meio a esses múltiplos problemas, um deles se destaca por sua amplitude: os resíduos sólidos, tendo este, impactos negativos que ultrapassam as questões ambientais, pois implicam conceitos econômicos, sociais, políticos entre outros (SILVA et al., 2012).

A Associação Brasileira de Normas Técnicas - NBR 10004/04 define resíduos sólidos como:

Resíduos nos estados sólido e semi-sólido, que resultam de atividades de origem industrial, doméstica, hospitalar, comercial, agrícola, de serviços e de varrição. Ficam incluídos nesta definição os lodos provenientes de sistemas de tratamento de água, aqueles gerados em equipamentos $e$ instalações de 


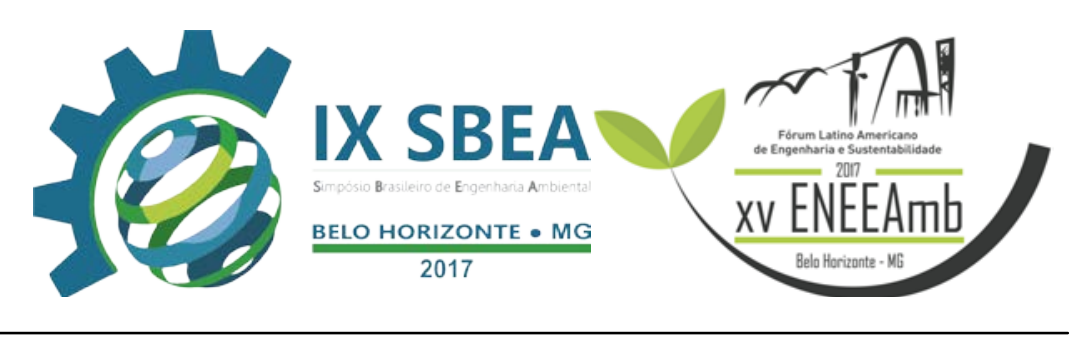

controle de poluição, bem como determinados líquidos cujas particularidades tornem inviável o seu lançamento na rede pública de esgotos ou corpos de água, ou exijam para isso soluções técnica e economicamente inviáveis em face à melhor tecnologia disponível (ABNT, 2004).

A geração, manejo e disposição final dos resíduos sólidos municipais estão entre os principais problemas ambientais dos municípios brasileiros; sendo o manejo e a disposição final, etapas determinantes para a qualidade de vida da população e do meio ambiente.

A Pesquisa Nacional de Saneamento Básico (PNSB) do ano de 2008 oferece uma visão detalhada sobre a oferta desse serviço em todos os municípios brasileiros (IBGE, 2017). Esta pesquisa registrou um percentual de 50,8\% dos municípios brasileiros que ainda recorriam aos lixões a céu aberto como destino principal de seus resíduos, apesar de obter uma redução anual desde dado em comparação as últimas décadas, este percentual deveria chegar a ser nulo, no qual a Lei $\mathrm{n}^{0} 12.305$, de 2 de agosto de 2010 (conhecida como Lei Nacional de Resíduos Sólidos) determinou a eliminação de lixões do Brasil até o ano de 2014.

O desenvolvimento de um projeto público adequado para a gestão dos resíduos sólidos urbanos está diretamente relacionado ao grau de envolvimento da população beneficiada. Logo, o conhecimento de alguns indicadores socioeconômicos da população beneficiada, e as necessidades existentes no local, é indispensável para nortear as políticas públicas na solução dos problemas relacionados á nossa sociedade (DONHA, 2002).

Em termos metodológicos, este estudo se apresenta, quanto aos fins, como descritivo, exploratório e, quanto aos meios, é avaliado como um estudo de caso. Este estudo tem por objetivo diagnosticar a eficiência do gerenciamento dos resíduos sólidos em uma área na zona periférica da cidade de Belém no estado do Pará.

\section{METODOLOGIA}

\section{1. Área de estudo:}




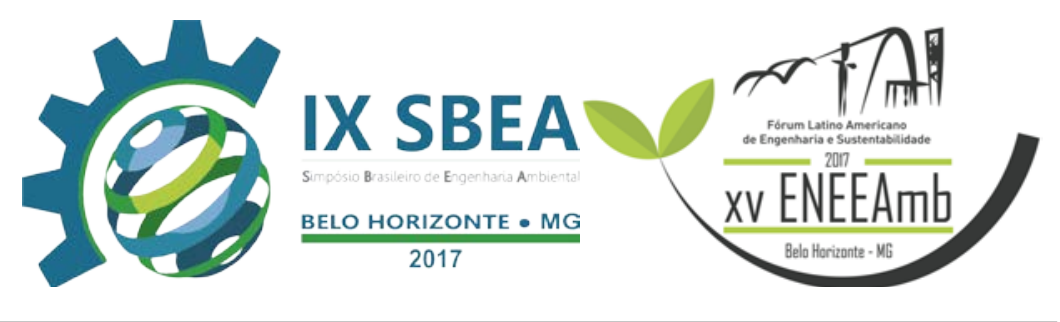

A área de estudo envolve um espaço localizado no bairro do Mangueirão na cidade de Belém-PA, que é uma localidade com alto déficits de saneamo básico. Possui uma área de 0,38 $\mathrm{km}^{2}$ (Figura 1), longitude - 48,43 e latitude -1,37. Não há dados específicos da quantidade de moradores nesta região, por isso estimou-se o número de habitantes residentes. No qual, Considerando uma média de 4 habitantes por domicílio (IBGE, 2010) 53 ruas e uma média de 40 casas por rua, contabilizou-se uma população aproximada de 8.500 habitantes.

Figura 1. Localização da área de estudo

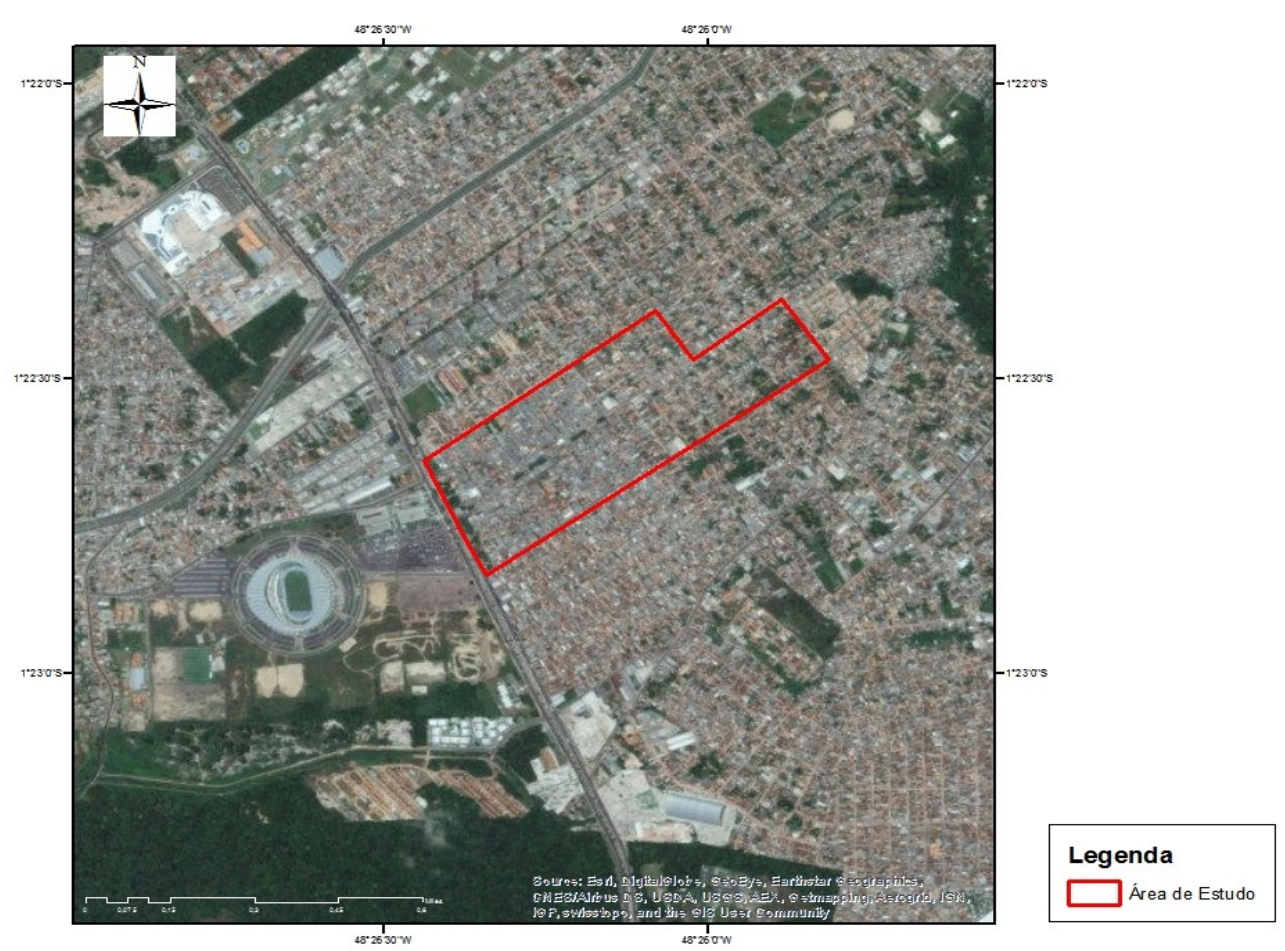

\subsection{Levantamento de dados:}

Esta etapa será realizada através de aplicação de questionários para uma parcela representativa da população, visto que é inacessível a investigação do tema com a população total. A fim de determinar uma parcela representativa da população, utilizouse a metodologia de Barbetta (2003), Equação (1) e Equação (2).

Com um erro amosral de 14\%, resultando em uma amostra representativa de 50 pessoas (representando 0,05\% da população total na área de estudo). As perguntas serão sobre conhecimentos e hábitos relacionados ao assunto (resíduos sólidos), também será 


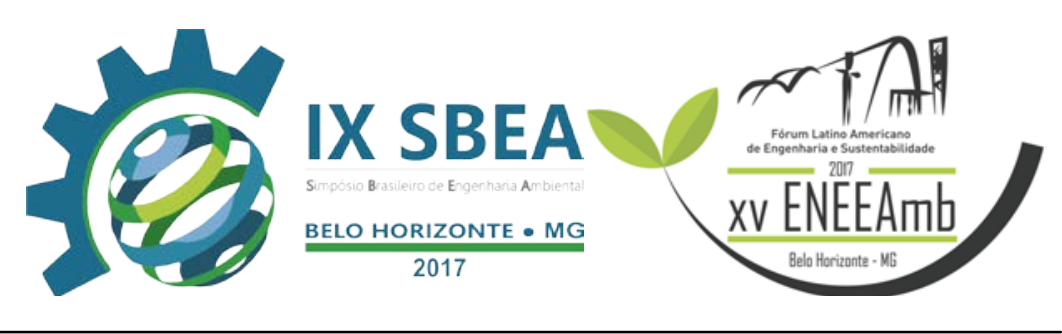

realizada uma análise exploratória do local, a fim de registrar a condição do amarzenamento dos resíduos e a limpeza das ruas, além de apresentar o perfil do morador desta localidade.

$$
n \geq \frac{n o \times N}{n o+N}
$$

Considerando:

$$
n o \geq \frac{1}{\varepsilon^{2}}
$$

Sendo, $n$ o número de elementos da amostra; noa primeira aproximação do número de elementos da amostra; $\mathrm{N}$ o número total de elementos da população; e $\varepsilon$ o erro amostral desejado.

\subsection{Análise de dados:}

Após aplicação dos questionários, foi realizada uma análise com a ferramenta EXCEL, buscando a melhor representação dos resultados obtidos no estudo.

\section{RESULTADOS E DISCUSSÃO}

O tratamento dos resíduos sólidos na cidade de Belém é feita no aterro sanitário no município de Marituba, cumprindo a lei Nacional dos Resíduos sólidos que ditou a interrupção de todos os lixões a céu aberto no Brasil até o ano de 2014.

Segundo o SNIS (2016), os dias para a realização da coleta do lixo ocorrem em uma frequência de 2 a 3 dias por semana em 56\% dos domicílios de Belém, e apenas em 44\% dos domicílios é feito a coleta de lixo diária. É pago uma taxa no boleto do IPTU para a realização dos servições de coleta regular, transporte e destinação final dos resíduos da cidade. Para o ano de 2014, foi gerado 362.701.100 kilogramas/ano de resíduos domiciliares, atendendo uma população de 1.318.215 habitantes, ou seja, cada habitante obtendo um gerador per capita de 0,76 kilogoramas/dia de resíduos na cidade. Considerando a quatidade per capita do morador de Belém, estima-se que o local de estudo seja gerador de 6.460 kilogramas/dia.

A coleta dos resíduos nos domicílios acontece em todas as ruas do bairro, e o acodicionamento do resíduo foi observada principalmente em sacolas plásticas que é colocado geralmente em lugares improvizados na frente da residência ou em coletores 


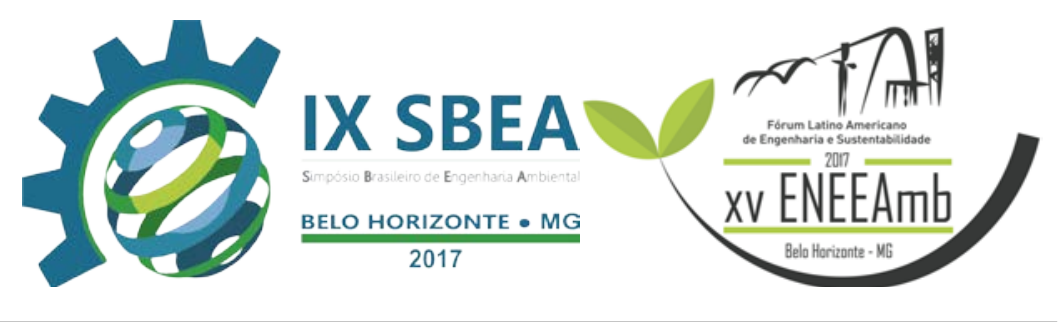

próprios de lixo. A coleta Seletiva é inexistente na área e nos bairros vizinhos, não tendo nenhum incentivo até então da iniciativa desse sistema no local, também é inexistente o emprego de lixeiras disponibilizado pela prefeitura da cidade nas ruas da área de estudo.

A Figura 2 mostra o hábito da população em usar sacolas plásticas fornecidas pelos supermercados e mercearias, pois são oferecida no ato das compras. No entanto, é comum haver rompimentos frequentes nos sacos plásticos utilizados para acondicionar os resíduos temporariamente nas ruas, tanto por animais quanto na transferência feita de forma manual para os caminhões da coleta.

Figura 2. Identificação do condicionamento dos resíduos sólidos pelos moradores

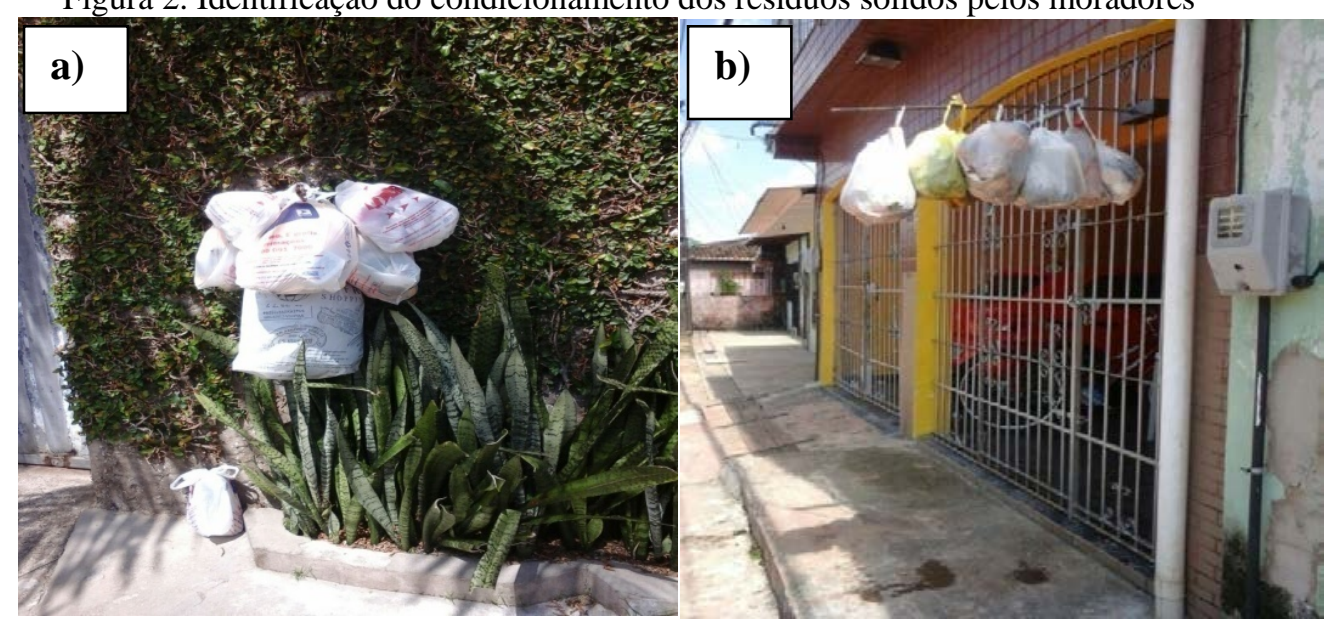

Segundo Oliveira (2006) o resíduo sólido depositado inadequadamente traz problemas de saúde, gerando doenças transmitidas por vetores que se proliferam no resíduo, como: mosquitos, moscas, ratos, baratas, bactérias e fungos. Se tivessem deposição correta, as cidades teriam um nível de poluição bem menor e os aspectos sanitários seriam favoráveis. Foram encontrados muitas situações que se encontravam nesse estado de degradação (Figura 3). 


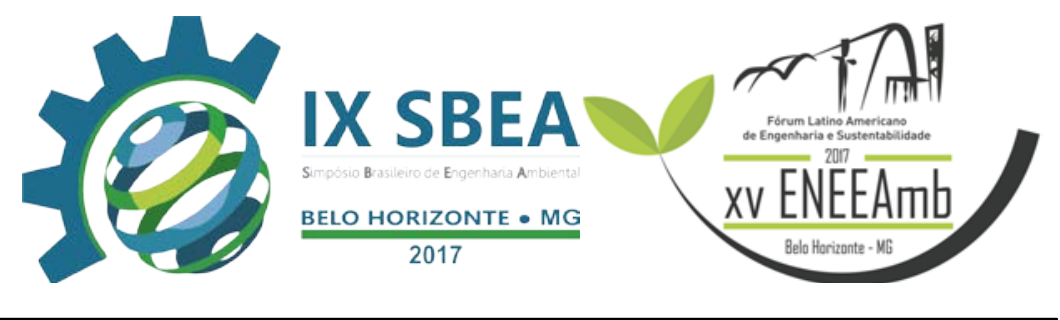

Figura 3. Situação de degradação do condicionamento dos resíduos sólidos

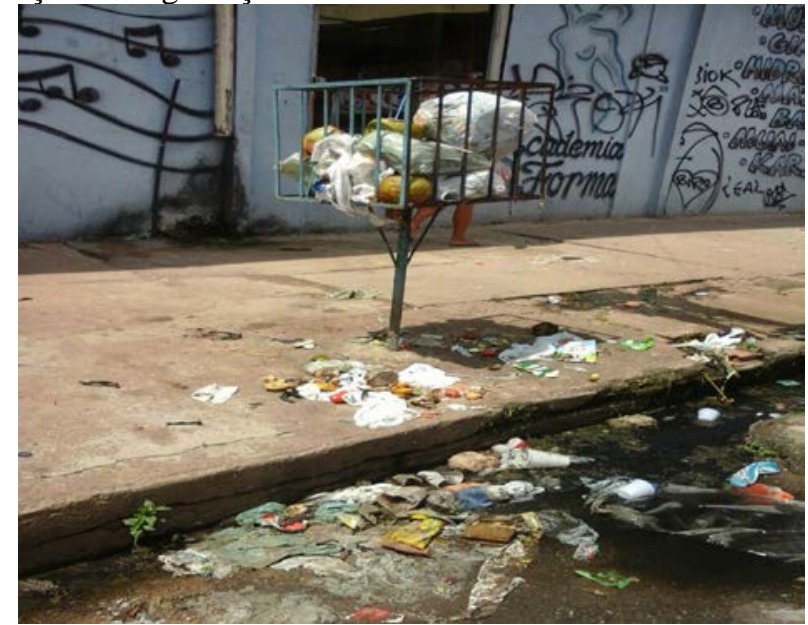

Na Figura 4 dispõe da situação de algumas bocas de lobo do local, que além destes não serem suficientes em quantidade ou volume para drenar totalmente as águas pluviais de todo o local de forma eficiente, os resíduos urbanos descartados na rua e até algumas folhagens, prejudicam ainda mais o sistema de drenagem do local.

Figura 4. Bocas de lobos na localidade

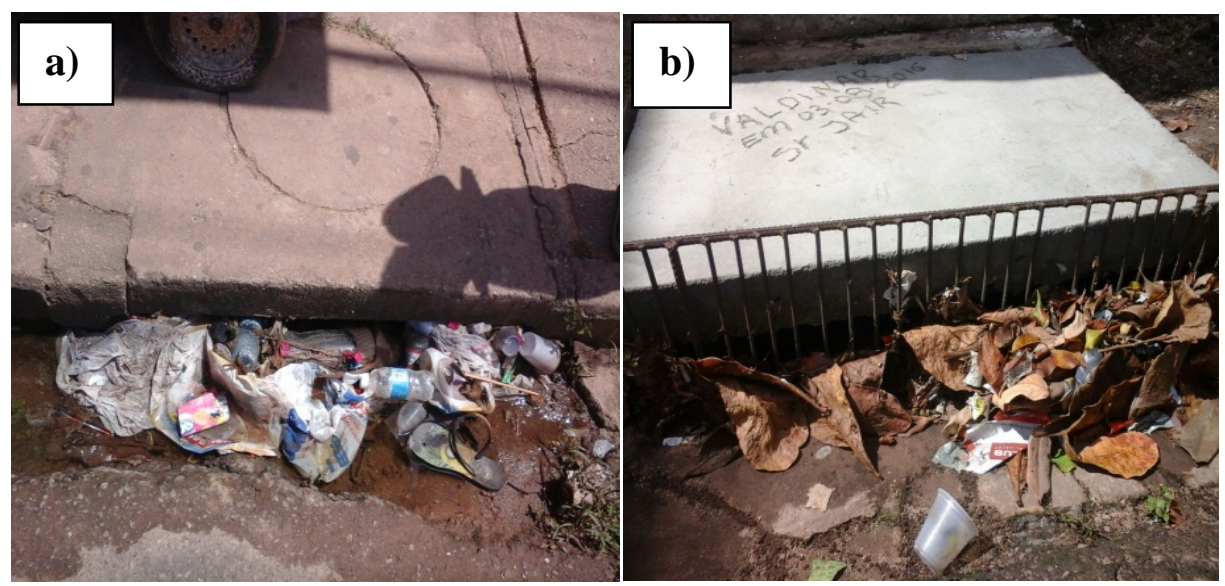

Através dos questionários, foi possível obter o perfil dos moradores. Sendo 54\% representando público feminino, e 46\% do público masculino (Figura 5). A escolaridade dos entrevistados obteve um maior percentual (60\%) para o ensino médio (completo e incompleto), seguido de 22\% para o ensino básico e 18\% para o ensino superior (Figura 6). Em relação à idade, o maior público foi de pessoas com 18 a 30 anos de idade, 


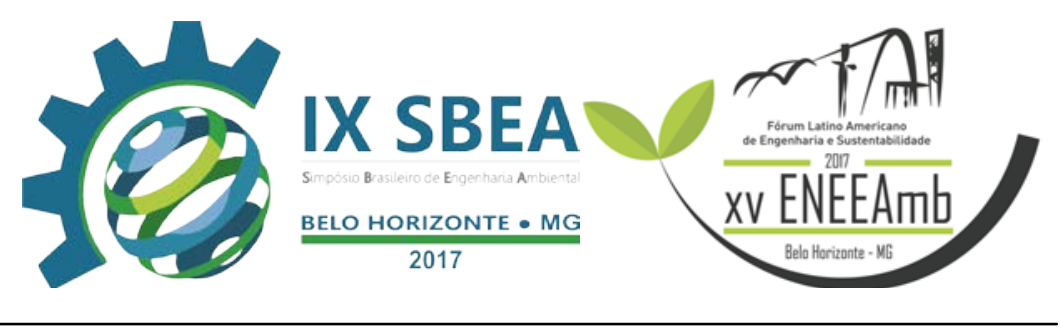

representando 30\% dos entrevistados; 28\% para idades entre 13 e 18 anos; $26 \%$ para 50 a 70 anos; e $16 \%$ para pessoas com idades entre 30 a 50 anos.

Figura 5. Gênero do público entrevistado

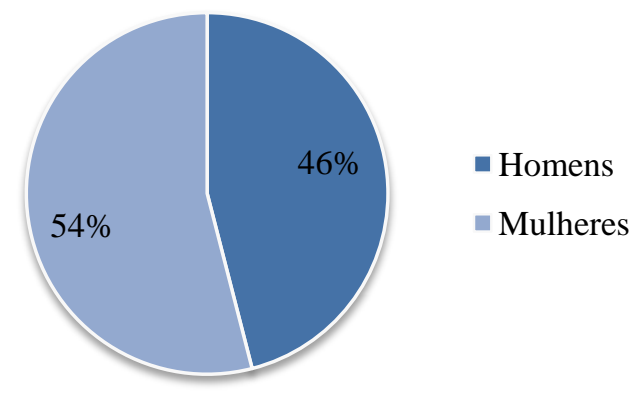

Figura 6. Escolaridade do público entrevistado

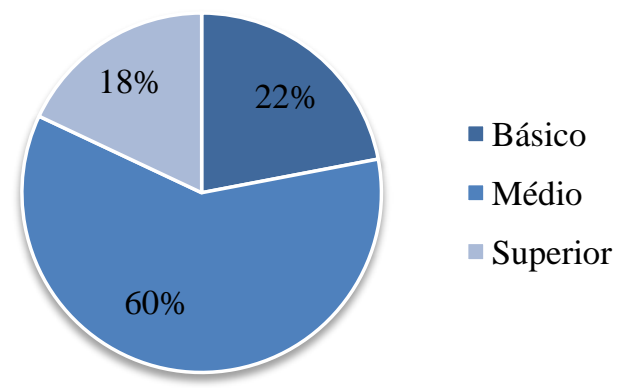

A renda familiar éstá disposto na Figura 8 , sendo $60 \%$ do público com uma renda de até 2 salários mínimos, destacando que a maioria da população residente é de baixa renda. Também, 20\% dos entrevistados não quiseram declarar a renda familiar, mesmo justificando que era uma pesquisa para fins acadêmicos e autônoma por parte dos entrevistados; 14\% possuem uma renda de 2 a 5 salários mínimos e apenas 6\% maior que 5 salários mínimos.

Figura 7. Idade do público entrevistado

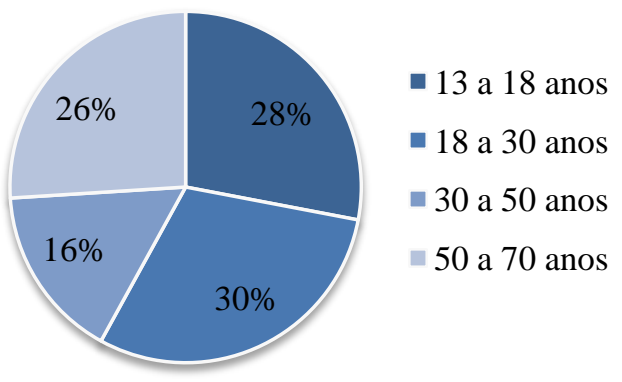

Figura 8. Renda do público entrevistado

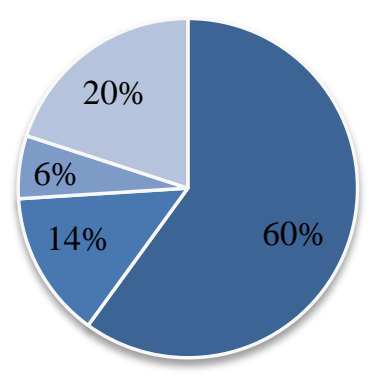

- Até 2 salários mínimos

Entre 2 e 5 salários mínimos

- Maior que 5 salários mínimos

Não declarado 


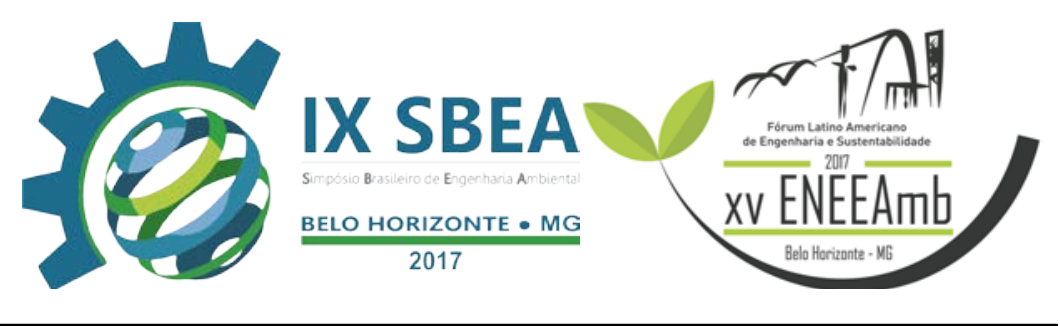

Na Tabela 1 está disposto as respostas das 11 questões aplicadas aos moradores da área de estudo. Sendo assim, ao perguntar se as pessoas sabiam o que era resíduos sólidos, $72 \%$ responderam que sim, porém foi perceptível na entrevista que o conceito para a população ainda é superficial. Apesar do termo resíduo sólido não ser comum para população, a maioria dos entrevistados confirmou conhecer a palavra, outros muitas das vezes confundindo com "lixo", apesar da confusão entre palavras a ideia não se torna totalmente invalida, visto que, a aceitação por projetos ambientais irá ser mais rápida e abrangente nesses casos.

Em todas as ruas da área de estudo possui a coleta dos resíduos, ou seja, existe o atendimento completo da população (100\%), e a pesperctiva da população em relação a isso, é positiva (Tabela 1). Entretanto, não há coleta seletiva na localidade, e apenas $58 \%$ dos entrevistados souberam responder o que significa o termo "coleta seletiva". Ressaltando que, alguns moradores afirmaram que separam o lixo (70\% das pessoas dizem saber separar os recicláveis), visto que há catadores que recolhem alguns tipos de material, como garrafas pet’s, papelão, etc., em que apenas $27 \%$ destas pessoas afirmam ter algum tipo de orientação para separar os recicláveis (pela TV, no trabalho entre outros). Se houvesse um projeto de coleta seletiva na área de estudo, 92\% dos entrevistados (Tabela 1) afirma interesse em colaborar separando os recicláveiso que é extremamente importante, pois ressalta que as pessoas aos poucos estão compreendendo e aceitando a inserção de projetos ambientais como este que visa aspectos economicos e socias. Apesar de $42 \%$ das pessoas dizerem não jogar os resíduos em lugares inapropiados, dos que relatam já ter descartado, 76\% dizem ter “consciência” das consequêcias desta ação. A queima do lixo a céu aberto foi negada por 57\% dos entrevistados, dentre os que afirmam já ter realizado este ato (43\%) são pessoas de idade adulta, que dizem não realizar mais com tanta frequencia esta queima.

Tabela 1. Questões respondidas pelo público entrevistado na área de estudo

\begin{tabular}{|c|l|c|c|}
\hline \multicolumn{2}{|c|}{ PERGUNTA } & SIM & NÃO \\
\cline { 3 - 4 } & & $\%$ & $\%$ \\
\hline 1 & Você sabe o que é Resíduos Sólidos? & 72 & 28 \\
\hline 2 & Existe coleta do lixo na sua rua? & 100 & - \\
\hline 3 & Você sabe o que é coleta seletiva? & 58 & 42 \\
\hline
\end{tabular}




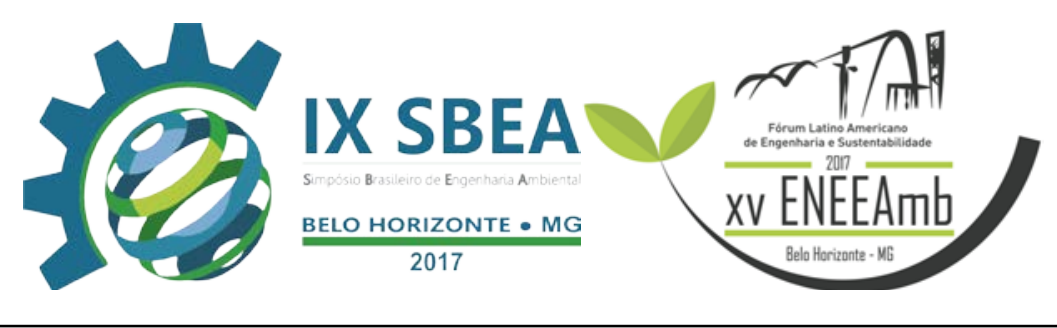

\begin{tabular}{|c|l|c|c|}
\hline 4 & Existe Coleta seletiva onde você mora? & - & 100 \\
\hline 5 & Você já descartou o lixo em lugares inapropriados? & 58 & 42 \\
\hline 6 & $\begin{array}{l}\text { Se sim, você está ciente das consequências desta } \\
\text { ação? }\end{array}$ & 76 & 24 \\
\hline 7 & Você acha que o lixo pode ser reutilizado? & 94 & 6 \\
\hline 8 & $\begin{array}{l}\text { Se houvesse um projeto de coleta seletiva em seu } \\
\text { bairro, você participaria separando os recicláveis? }\end{array}$ & 92 & 8 \\
\hline 9 & Você Sabe Separar os recicláveis & 70 & 30 \\
\hline 10 & Teve alguma orientação para isso? & 43 & 73 \\
\hline 11 & Você já realizou a queima do lixo a céu aberto? & & 57 \\
\hline
\end{tabular}

Loureiro (2011) destaca que os esforços para construção de uma sociedade consciente se encontra em contradição, pois não há uma coerencia entre pensamento e prática para que haja mudança de compotamentos e/ou habitos.

\section{CONCLUSÕES/RECOMENDAÇÕES}

Diante dos resultados obtidos, este trabalho apresentou a situação dos resíduos sólidos na área de estudo, com importante colaboração para a visualização de problemas do local. Resultando na percepção do conhecimento das pessoas residentes, e o que representa não só neste bairro, mas em toda a cidade de Belém. A separação dos resíduos já é feita por alguns moradores, que já conseguem entender a importância da educação ambiental. Porém, o ideal é que toda população esteja ciente do funcionamento dos despejos dos resíduos gerados, e que os mesmos tenham a disposição o incentivo a prática do correto gerenciamento. A coleta seletiva, por exemplo, deve atingir uma porcentagem maior da população. Portanto, são necessárias ações governamentais e propostas junto à população a fim de estabelecer metas para o avanço na resolução dos problemas encontrados, para a conservação do meio ambiente e qualidade de vida no local, além de cumprir as metas dispostas no Plano Diretor da cidade de Belém.

\section{REFERÊNCIAS BIBLIOGRÁFICAS}




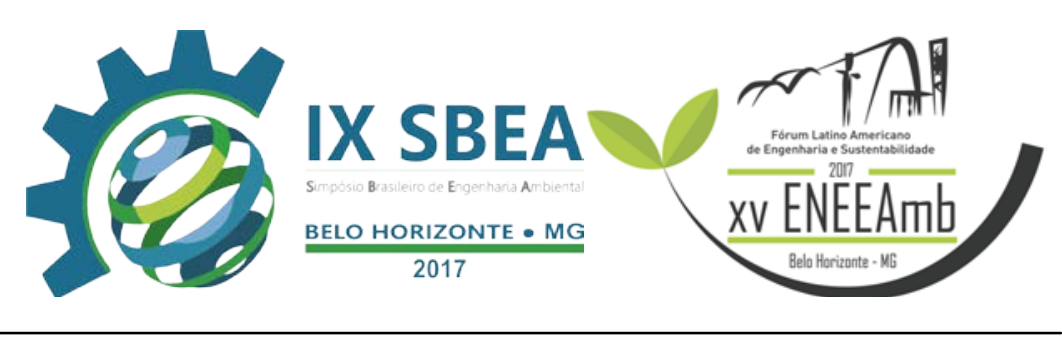

ABNT. (ASSOCIAÇÃO BRASILEIRA DE NORMAS TÉCNICAS). Resíduos Sólidos. Classificação NBR 10.004, Rio de Janeiro, 1987

DONHA, M. S. Conhecimento E Participação Da Comunidade No SistemaDe Gerenciamento De Resíduos Sólidos Urbanos: O Caso De Marechal Cândido Rondon - Pr. Florianópolis, 116p., 2002. Dissertação (Mestrado) - Universidade Federal De Santa Catarina.

IBGE: Instituto Brasileiro de Geografia e Estatística. Disponível em: Acesso em: http://www.ibge.gov.br/. Acesso em: 14 jan. 2017.

SILVA, S. S. F. da; SANTOS, J. G.; CÂNDIDO, G. A.; RAMALHO, A. M. C. Indicador de Sustentabilidade Pressão -Estado - Impacto - Resposta no Diagnóstico do Cenário Sócio Ambiental resultante dos Resíduos Sólidos Urbanos em Cuité, PB. REUNIR - Revista de Administração, Contabilidade e Sustentabilidade, v. 2, n. 3, p. 76-93, 2012.

SNIS: Sistema Nacional de Informação sobre Saneamento. Disponível em: http://app.cidades.gov.br/serieHistorica/. Acesso em: 02 de dez. 2016.

LOUREIRO, C.; LAYRARGUES, P.; CASTRO, R. Educação Ambiental: repensando o espaço da cidadania. São Paulo: Cortez Editora, 2011, 264 p.

OLIVEIRA, N. A. S. A percepção dos resíduos sólidos (lixo) de origem domiciliar no Bairro Cajuru, Curitiba-PR: um olhar reflexivo a partir da educação ambiental. Curitiba, 160 p., 2006. Tese (Mestrado) - Universidade Federal do Paraná. 